\title{
A systematic review of the challenges to implementation of the patient-centred medical home: lessons for Australia
}

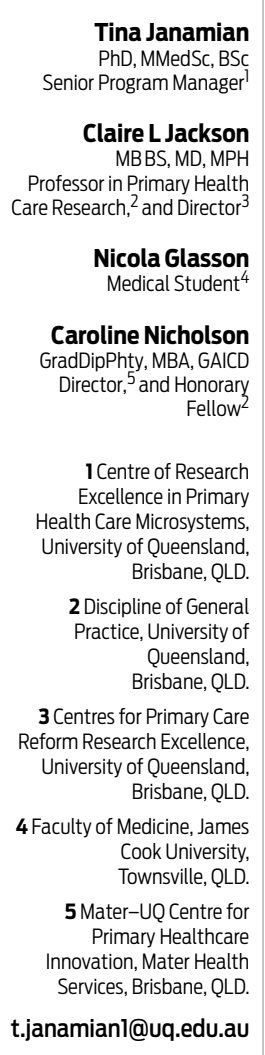

doi: 10.5694/mjal4.00295

Online first 21/07/14 ustralia's first National Primary Health Care Strategy ${ }^{1}$ and resulting National Primary Health Care Strategic Framework ${ }^{2}$ initiated growing interest and development in our primary care sector, particularly general practice. Clinicians, governments and organisations are now actively searching for new approaches, models of care and business levers to support the primary care quality, efficiency and access gains sought. In December 2012, then Minister for Health Tanya Plibersek announced a focus on the patient-centred medical home (PCMH) as a model of interest. ${ }^{3}$ The Royal Australian College of General Practitioners (RACGP) has also been a consistent champion of the model, urging adoption of its elements as part of current reforms and calling for the federal government to fund and implement key elements in its 2013-14 Budget submission. ${ }^{4}$

The PCMH concept of care was introduced by the American Academy of Pediatrics in 1967, and was adopted in 2002 by the family medicine specialty. Four major primary care physician associations in the United States, along with other stakeholders, formed the Patient-Centered Primary Care Collaborative (PCPCC), and in 2007 endorsed the Joint principles of the patient-centered medical home. ${ }^{5}$ These include: access to a personal physician; physiciandirected medical practice; whole-person orientation; care coordination and/or integration; quality and safety benchmarking through evidence-based medicine and clinical decision support tools; enhanced care availability after hours and via e-health; and practice payment reform. We used this definition of PCMH in our review because it concords strongly with the RACGP's statement, A quality general practice of the future, ${ }^{6}$ endorsed by all general practice organisations nationally in 2012.

There is evidence that adoption of the PCMH model can improve: access to care; ${ }^{7-10}$ clinical parameters and outcomes; ${ }^{11-15}$ management of chronic and complex disease care, ${ }^{7-9,11,12,14-22}$ preventive care services (eg, cholesterol tests, influenza vaccinations, prostate examinati ons); $; 10,12,13,17,18,20,23-26$ and provide improved condition-specific quality of care ${ }^{14,15,18,19,22,27}$ and palliative care services. ${ }^{8}$ Data also indicate that the PCMH model can decrease the use of inappropriate medications, ${ }^{8,22,23}$ and significantly reduce avoidable hospital admissions and readmissions, emergency department use and overall care costs. $., 14,22,28-31$

While the PCMH model shows promise in transforming the primary care system into a more integrated and comprehensive model, studies report challenges and barriers to the implementation and adoption of this model. Before its potential can be achieved, more robust information is needed on the actual change process, challenges and barriers associated with implementation of this model. . $2,33^{3}$

We undertook a systematic review to identify the major challenges and barriers to implementation and adoption of the PCMH model. The findings from this review will

\section{Abstract}

Objective: To review the available literature to identify the major challenges and barriers to implementation and adoption of the patient-centred medical home $(\mathrm{PCMH})$ model, topical in current Australian primary care reforms.

Study design: Systematic review of peer-reviewed literature.

Data sources: PubMed and Embase databases were searched in December 2012 for studies published in English between January 2007 and December 2012.

Study selection: Studies of any type were included if they defined PCMH using the Patient-Centered Primary Care Collaborative Joint Principles, and reported data on challenges and barriers to implementation and adoption of the PCMH model.

Data extraction: One researcher with content knowledge in the area abstracted data relating to the review objective and study design from eligible articles. A second researcher reviewed the abstracted data alongside the original article to check for accuracy and completeness.

Data synthesis: Thematic synthesis was used to in three stages: free line-by-line coding of data; organisation of "free codes" into related areas to construct "descriptive" themes and develop "analytical" themes. The main barriers identified related to: challenges with the transformation process; difficulties associated with change management; challenges in implementing and using an electronic health record that administers principles of $\mathrm{PCMH}$; challenges with funding and appropriate payment models; insufficient resources and infrastructure within practices; and inadequate measures of performance.

Conclusion: This systematic review documents the key challenges and barriers to implementing the PCMH model in United States family practice. It provides valuable evidence for Australian clinicians, policymakers, and organisations approaching adoption of PCMH elements within reform initiatives in this country.

provide lessons for Australian primary health care reform and future PCMH initiatives in Australia.

\section{Methods}

A complete description of the methods is provided in Appendix 1 (online at mja.com.au).

In December 2012, we searched the PubMed and Embase databases for studies published between January 2007 and December 2012 using the search terms patient centered medical home, patient centred medical home, medical home, or $P C M H$. Appendix 2 (online at mja.com.au) provides details of the search strategy. A snowballing strategy was used to identify other related citations through the reference list of all reviewed articles.

Abstracts were included if they met the following inclusion criteria: 1) published between 2007 and 2012; 2) in English; 3) reported information or data related to the 
review objective; 4) defined PCMH using the PCPCC Joint Principles, or at least mentioned some of its components. ${ }^{5}$ There were no restrictions on study design or country of study.

Articles included during the initial screening by either reviewer underwent full-text screening. One reviewer with expertise in the area reviewed the full text of each article and indicated a decision to include or exclude the article for data abstraction. We applied 10 quality criteria that were common to sets of criteria proposed by research groups for qualitative research (Box 1). ${ }^{34-36}$ Two reviewers independently assessed the quality of each study, and discrepancies were resolved through discussion.

\section{Data extraction and synthesis}

A data extraction form was created by the investigative team to assist in systematically extracting information on the study design (type of study, methodology and setting) and key findings related to the review objective. One researcher with content knowledge in the area abstracted the data, while a second researcher reviewed the abstracted data alongside the original article to check for accuracy and completeness.

Thematic synthesis was used in three stages: the free line-by-line coding of data; the organisation of these "free codes" into related areas to construct descriptive themes; and the development of analytical themes. ${ }^{37}$ Data were configured at a study level using a top-down approach, which allowed individual findings from broad study types to be organised and arranged into a coherent theoretical rendering. ${ }^{38}$ Synthesis matrices allowed data to be recorded, synthesised and compared.

\section{Results}

The search strategy identified 2690 citations, of which 28 studies met the inclusion criteria (Box 2). All studies were from the US. This was not surprising, as the PCMH model is a North American model and the PCPCC Joint Principles of the PCMH definition we used as part of the inclusion criteria is from the US. Of the 28 articles, there were nine exploratory studies, 13 descriptive studies, and six experimental or quasi-experimental studies. All studies met five or more of the 10 quality criteria, and nine of the 28 studies met all 10 quality criteria. Descriptions of included studies (including type of study, method, setting and quality rating) are provided in Appendix 3 (online at mja.com.au).

This systematic review identified six key overlapping challenges and barriers to implementation and adoption of the PCMH model. These are presented below, and Appendix 4 (online at mja.com.au) includes a summary table of themes identified in each study.

\section{Challenges with transformation and change management in adopting a PCMH model}

Eleven studies discussed varying challenges and barriers to transforming to a PCMH model. Transformation calls for significant changes in the routine operations of practices, and these are difficult to achieve and require more than a series of incremental changes. ${ }^{16,27,39-44}$ Key requirements are: long-term commitment, 17,39,43,45 local variation, 17,39,45 a focus on patient-centredness, $39,45,46$ and support through

\section{Criteria for assessing quality of studies ${ }^{34-36}$}

Aims and objectives clearly stated

An explicit theoretical framework, study design and/or literature review

A clear description of context

A clear description of the sample and how it was recruited

A clear description of methods used to collect and analyse data

Attempts made to establish the reliability or validity of data analysis

- Inclusion of sufficient original or synthesised data to mediate between evidence and interpretation

- Use of verification procedure(s) to establish credibility

Conclusions supported by results

Relevance

\section{Flow diagram outlining selection process of studies for analysis}

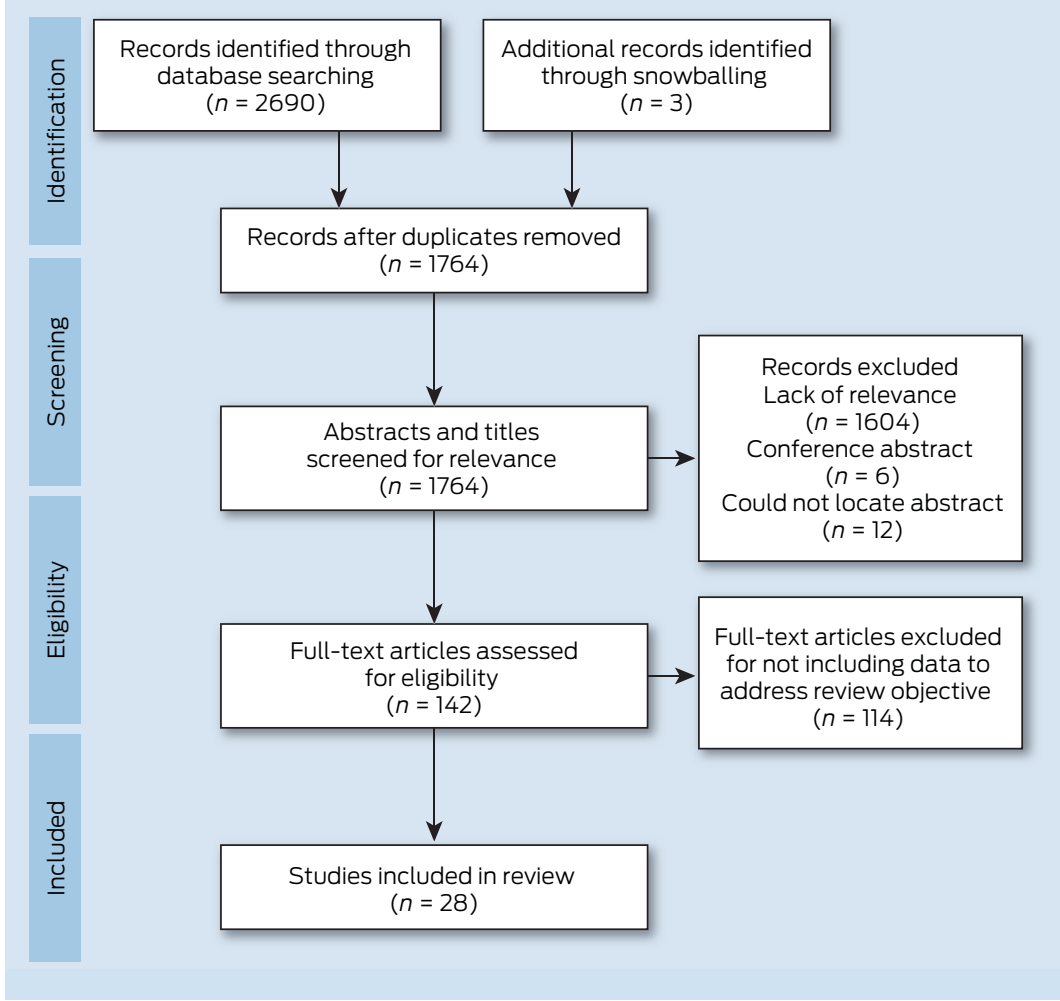

reform of the larger delivery system to integrate primary care within it. ${ }^{17,27,40,47}$ Even with external payment reform, practices need extensive assistance coaching from external facilitators and expert consultants to transform to a PCMH. ${ }^{16,27,39,43}$

There were reported challenges ${ }^{41,43,44,48}$ relating to a shift in paradigm for individuals and practices, which required them to move away from a physician-centred approach towards a team approach shared among other practice staff. $17,39,43,44,49$ Transformation efforts were slowed or ceased by ineffective change management processes; 39,50 lack of leadership, ${ }^{51,52}$ readiness for change, communication and trust; ${ }^{17,44,50-53}$ and culture. ${ }^{39,43,52,53}$ Misinformation or lack of understanding about the PCMH could lead to misunderstandings about what was being asked of practices and staff, $41,45,53$ causing resistance to change ${ }^{39,43}$ Furthermore, practices without capacity for organisational learning and development, or what is called "adaptive reserve" (such as a healthy relationship infrastructure, an aligned management 
model and facilitated leadership), were more likely to experience "change fatigue", $17,41,43,44,50,54$ and less likely to successfully implement the PCMH model. ${ }^{17,43,44}$

\section{Difficulties with electronic health records}

Implementing an electronic health record (EHR) with a clear, meaningful use, and which administers the principles of $\mathrm{PCMH}$, has been a difficult task for primary care practices in transition. ${ }^{17,41,46,55}$ Implementation and use of an integrated EHR has proved to be more difficult than originally envisioned, ${ }^{27,39,41,43,52,53}$ requiring significant investment of time, effort, resources (eg, new equipment, training material) and money. ${ }^{39,41,44,52,54}$ Reported challenges related to setting up EHRs at practices, and providing ongoing technical support and resources to service.

There were also difficulties with functionality (eg, EHR could not provide data for population management; a disease registry was absent or extremely awkward to activate; and e-visits such as telephone, email or video consultations presented challenges), and use of EHRs (eg, accessing electronic records in a timely, easily digestible manner, and accuracy and reliability of information in the EHR). ${ }^{39,42,48,50,51}$ Furthermore, single-practice EHRs were reported as insufficient and a barrier to effective coordinated care ${ }^{47}$ and the lack of interoperability of EHRs hindered collaboration between providers, crucial to the PCMH model. ${ }^{17,46,47,52,54}$

\section{Challenges with funding and payment models}

Sixteen studies reported challenges with the current funding models for PCMH. Most stated that current available funding and reimbursements were likely to be inadequate for the transitional costs and sustainability of the $\mathrm{PCMH},{ }^{39-42,45,49,50,54-59}$ and the essential functions of the PCMH are not supported by traditional fee structures. ${ }^{41,47,49,55,56}$ Many studies recommended that new payment structures and incentives for practices and providers be developed to support implementation and sustainability of the PCMH model. 39,40,43,45,49,50,52,54-59

\section{Insufficient practice resources and infrastructure}

Eighteen studies reported barriers related to insufficient resources within practices to implement the PCMH model. These included lack of resources (eg, equipment, human resources, training material), structural capabilities, time and financial capacity to develop the necessary building blocks to transform their practice into a PCMH.17,45,51-53,59 Substantial support (including non-monetary support) and resources were required to implement change at the practice level. ${ }^{16,27,41,49,50,57,58,60}$ Smaller practices typically could not employ the same resources as larger facilities due to budget and resources constraints. Therefore, implementation at small practices was challenging due to lack of internal capabilities. ${ }^{21,41,42,44,61}$

\section{Inadequate measures of performance and inconsistent accreditation and standards}

There were several reported challenges relating to variations in PCMH standards, inadequate accreditation and measures of performance. 16,17,39-42,45,47,56 Most tools developed to measure achievement of the medical home did not directly correspond to the seven Joint Principles that define the $\mathrm{PCMH}$, and many of these principles were difficult to measure. ${ }^{45}$ Furthermore, accreditation does not yet capture all the key aspects required for a fully functioning medical home, ${ }^{16}$ and the criteria for evaluating PCMH were inconsistent. ${ }^{56}$ Establishing standards, measures and targets proved difficult. ${ }^{16,17,40,42}$

\section{Discussion}

In our systematic review, we found evidence of challenges and barriers to implementation of a PCMH model, including difficulties with transformation to a new system, change management issues, adopting EHRs and adapting payment models. Other challenges were inadequate resources, performance measurement and accreditation.

Our findings have significant importance for current Australian reform initiatives. The RACGP, as part of its 2013-14 Budget submission, called for the federal government to fund and implement key elements of the PCMH, as it "encapsulates the very definition of [future] general practice in Australia". ${ }^{4}$ Evidence-based assessment of the barriers and enablers to such transition presented in this article is an essential step to effective implementation.

As in the US, primary care practices in this country are challenged by growing complexity of care, accreditation pressures, and perverse funding and reward systems. Clinicians and organisations are often on the receiving end of policy implementation that is top-down rather than bottom-up, and, as small businesses, struggle to adapt in the defined time frames. ${ }^{62,63}$ Our review also notes the importance of reform across the larger delivery system to integrate primary care change within it. It demonstrates the importance of a long-term and tangible commitment to change adoption at the practice level (strong "adaptive reserves"), with a focus on teamwork, leadership, highquality communication, staff development and ongoing support for a culture of change. Appropriate practice resourcing for infrastructure and system support over the "transformation" period is essential, as identified in our National Primary Health Care Strategy.,

The literature also highlights the importance of practice and practitioner funding that promotes patient centredness, preventive health, and a focus on complex chronic disease support, case management and hospital avoidance. This is timely in the Australian context, as is the focus on EHRs that promote care coordination, quality and safety benchmarking, and clinical decision support. ${ }^{54}$

Finally, our findings suggest that reform initiatives should involve accreditation review, such that these frameworks reflect measures of performance and standards that match the key benchmarks of importance, with minimal administrative barriers. Such initiatives are in early development, with the RACGP and Australian Commission on Quality and Safety in Health Care partnering in a review of accreditation process and outcome. ${ }^{64}$

Our review had some limitations. The search strategy did not include grey literature, and unpublished evaluation studies or reports may have been missed. There could also be other challenges or barriers not reported in the reviewed publications. The review was limited to studies that used the Joint Principles, ${ }^{5}$ because this definition concords strongly with the RACGP's A quality general practice of the future, ${ }^{6}$ but may have missed literature published 
outside this definition. Data abstraction from qualitative studies can be complicated by the varied reporting styles. ${ }^{65}$ Relevant study "data" were often not presented in the results section, but integrated into the discussion or recommendations. Hence, a second researcher reviewed abstracted data alongside the original article to check for accuracy and completeness. Furthermore, the synthesis of qualitative data is problematic and dependent on the judgement and insight of the researchers (interpretation bias). ${ }^{37,66,67}$ To limit this bias, two independent researchers were used in the synthesis process.

Our systematic review indicates that implementation of significant primary care change should be cognisant of several considerations, mostly at the practice-practitioner interface. It comes at an important juncture for Australian health care reform, with reviews into the personally controlled electronic health record and Medicare Locals, and recent ministerial statements regarding funding reform for chronic disease management likely to have a major impact on the sector. For policymakers, they underline the approach and resourcing required to effectively influence service delivery. For clinicians, they highlight the teamwork, commitment and practice infrastructure critical to success. Australian health care reforms demand "a stronger, more robust primary health care system". ${ }^{2}$ Addressing documented barriers to change adoption relevant in the Australian context will be a critical evidence-into-policy initiative.

Acknowledgements: We thank the Australian Primary Health Care Research Institute for funding this commissioned research, Lars Eriksson (University of Queensland) for assistance with the literature searches, and Susan Upham (University of Queensland, Discipline of General Practice) for assisting with this systematic review as a second reviewer assessing the quality of studies.

\section{Competing interests: No relevant disclosures.}

\section{Provenance: Commissioned; externally peer reviewed.}

1 Australian Government Department of Health and Ageing. Building a 21 st century primary health care system. Australia's first National Primary Health Care Strategy 2010. Canberra: DoHA, 2010. http://www.health.gov. au/internet/yourhealth/publishing.nsf/Content/3EDF5889BEC00D98CA2 579540005F0A4/\$File/6552\%20NPHC\%201205.pdf (accessed Jan 2014).

2 Australian Government Department of Health and Ageing. National Primary Health Care Strategic Framework. Canberra: DoHA, 2013. http:// www.health.gov.au/internet/publications/publishing.nsf/Content/NPHCStrategic-Framework/\$File/nphc_strategic_framework_final.pdf (accessed Jan 2014).

3 Kaye B. One step closer to "medical home". Medical Observer 2013; 26 Mar. http://www.medicalobserver.com.au/news/one-step-closer-to-medicalhome (accessed Apr 2014).

4 Royal Australian College of General Practitioners. RACGP submission to the Minister for Health: federal Budget 2013-2014. Laying foundations for the medical home. Melbourne: RACGP, 2013. http://www.patientconnect.com. au/ws-content/uploads/News_artile_-_RACGP_pre_budget_submission. pdf (accessed Feb 2014).

5 American Academy of Family Physicians, American Academy of Pediatrics, American College of Physicians, American Osteopathic Association. Joint principles of the patient-centered medical home, March 2007. Washington, DC: American College of Physicians, 2007. http://www.acponline.org/ running_practice/delivery_and_payment_models/pcmh/demonstrations/ jointprinc_05_17.pdf (accessed Dec 2012).

6 Royal Australian College of General Practitioners. A quality general practice of the future: the RACGP presidential task force on health reform. Melbourne: RACGP, 2012. http://www.racgp.org.au/download/Documents/ Policies/Health\%20systems/quality-general-practice-of-the-future-2012. pdf (accessed Apr 2012).

7 Amiel JM, Pincus HA. The medical home model. New opportunities for psychiatric services in the United States. Curr Opin Psychiatry 2011; 24: 562-568.

8 McCarthy D, Mueller K, Tillmann I. Group health cooperative: reinventing primary care by connecting patients with a medical home. New York: The Commonwealth Fund, 2009. http://www.commonwealthfund.org/ / media/files/publications/case-study/2009/jul/1283_mccarthy_grouphealth_case_study_72_rev.pdf (accessed Jun 2014).

9 Ferrante JM, Balasubramanian BA, Hudson SV, et al. Principles of the patient-centered medical home and preventive services delivery. Ann Fam Med 2010; 8: 108-116.

10 Aysola J, Bitton A, Zaslavsky AM, et al. Quality and equity of primary care with patient-centered medical homes. Results from a national survey. Med Care 2013; 51: 68-77.

11 Berdine HJ, Skomo ML. Development and integration of pharmacist clinical services into the patient-centered medical home. J Am Pharm Assoc (2003) 2012; 52: 661-667.

12 Gabbay RA, Bailit MH, Mauger DT, et al. Multipayer patient-centered medical home implementation guided by the chronic care model. Jt Comm J Qual Patient Saf 2011; 37: 265-273.

13 O'Donnell J, Shull C. Winkler A, et al. Increased clinical outcomes at year follow-up found in a diabetic patient-centered medical home pilot program. J Clin Hypertens (Greenwich) 2011; 13 Suppl: A156-A157. doi: 10.1111/j. 1751-7176.2011.00459.x

14 Maeng DD, Graf TR, Davis DE, et al. Can a patient-centered medical home lead to better patient outcomes? The quality implications of Geisinger's ProvenHealth Navigator. Am J Med Qual 2012; 27: 210-216.

15 Rosenthal TC. The medical home. Growing evidence to support a new approach to primary care. J Am Board Fam Med 2008; 21: 427-440.

16 Bitton A, Martin C, Landon BE. A nationwide survey of patient centered medical home demonstration projects. J Gen Intern Med 2010; 25: 584-592.

17 Crabtree BF, Nutting PA, Miller WL, et al. Summary of the National Demonstration Project and recommendations for the patient-centered medical home. Ann Fam Med 2010; 8 Suppl 1: S80-S90; S92.

18 Grumbach K, Grundy P. Outcomes of implementing patient-centered medical home interventions. A review of the evidence from prospective evaluation studies in the United States. Updated November 2010. Washington, DC: Employee Benefit Research Institute, 2010. http://www. ebri.org/pdf/programs/policyforums/Grundy-outcomes1210.pdf (accessed Jun 2014).

19 O'Toole TP, Pirraglia PA, Dosa D, et al. Building care systems to improve access for high-risk and vulnerable veteran populations. J Gen Intern Med 2011; 26 Suppl 2: 683-688.

20 Raskas RS, Latts LM, Hummel JR, et al. Early results show WellPoint's patient-centered medical home pilots have met some goals for costs, utilization, and quality. Health Aff (Millwood) 2012; 31: 2002-2009.

21 Rich EC, Lipson D, Libersky J, et al. Organizing care for complex patients in the patient-centered medical home. Ann Fam Med 2012; 10: 60-62.

22 Rosenberg CN, Peele P, Keyser D, et al. Results from a patient-centered medical home pilot at UPMC health plan hold lessons for broader adoption of the model. Health Aff (Millwood) 2012; 31: 2423-2431.

23 DeVries A, Li CH, Sridhar G, et al. Impact of medical homes on quality, health care utilization, and costs. Am J Manag Care 2012; 18: 534-544.

24 Jackson CL. Australian general practice. Primed for the "patient-centred medical home"? Med J Aust 2012; 197: 365-366.

25 Pandhi N, DeVoe JE, Schumacher JR, et al. Number of first-contact access components required to improve preventive service receipt in primary care homes. J Gen Intern Med 2012; 27: 677-684.

26 Jackson GL, Powers BJ, Chatterjee R, et al. The patient-centered medical home. A systematic review. Ann Intern Med 2013; 158: 169-178.

27 Jaen CR, Ferrer RL, Miller WL, et al. Patient outcomes at 26 months in the patient-centered medical home National Demonstration Project. Ann Fam Med 2010; 8 Suppl 1: S57-S67; S92.

28 Reid RJ, Fishman PA, Yu O et al. Patient-centered medical home demonstration. A prospective, quasi-experimental, before and after evaluation. Am J Manag Care 2009; 15: e71-e87.

29 Institute for Healthcare Improvement. Genesys HealthWorks integrates primary care with health navigator to improve health, reduce costs. Cambridge, Mass: IHI, 2009. http://www.ihi.org/Engage/Initiatives/ TripleAim/Documents/IHITripleAimGenesysHealthSystemSummaryofSucc essJul09v2.pdf (accessed Dec 2012).

30 Leff B, Reider L, Frick KD, et al. Guided care and the cost of complex healthcare. A preliminary report. Am J Manag Care 2009; 15: 555-559.

31 Steiner BD, Denham AC, Ashkin E, et al. Community care of North Carolina. Improving care through community health networks. Ann Fam Med 2008; 6: 361-367.

32 Barr MS. The need to test the patient-centered medical home. JAMA 2008; 300: 834-835.

33 Peikes D, Zutshi A, Genevro JL, et al. Early evaluations of the medical home. Building on a promising start. Am J Manag Care 2012; 18: 105-116.

34 Harden A, Garcia J, Oliver S, et al. Applying systematic review methods to studies of young people's views. J Epidemiol Community Health 2004; 58: 794-800. 
35 Kmet LM, Lee RC, Cook LS. Standard quality assessment criteria for evaluating primary research papers from a variety of fields. Edmonton, Canada: Alberta Heritage Foundation for Medical Research, 2004. http:// www.ihe.ca/documents/HTA-FR13.pdf (accessed Dec 2012).

36 Pawson R, Greenhalgh T, Harvey G, et al. Realist review - a new method of systematic review designed for complex policy interventions.J Health Serv Res Policy 2005; 10 Suppl 1: 21-34.

37 Thomas J, Harden A. Methods for the thematic synthesis of qualitative research in systematic reviews. BMC Med Res Methodol 2008; 8: 45.

38 Sandelowski M, Voils Cl, Leeman J, et al. Mapping the mixed methods mixed research synthesis terrain. J Mix Methods Res 2012; 6: 317-331.

39 Nutting PA, Miller WL, Crabtree BF, et al. Initial lessons from the first national demonstration project on practice transformation to a patientcentered medical home. Ann Fam Med 2009; 7: 254-260.

40 Stenger RJ, Devoe JE. Policy challenges in building the medical home. Do we have a shared blueprint? J Am Board Fam Med 2010; 23: 384-392.

41 Green EP, Wendland J, Carver MC, et al. Lessons learned from implementing the patient-centered medical home. Int J Telemed Appl 2012; 2012: 103685. doi: 10.1155/2012/103685.

42 Harbrecht MG, Latts LM. Colorado's Patient-Centered Medical Home Pilot met numerous obstacles, yet saw results such as reduced hospital admissions. Health Aff (Millwood) 2012; 31: 2010-2017.

43 Nutting PA, Crabtree BF, Miller WL, et al. Transforming physician practices to patient-centered medical homes. Lessons from the national demonstration project. Health Aff (Millwood) 2011; 30: 439-445.

44 Nutting PA, Crabtree BF, Miller WL, et al. Journey to the patient-centered medical home. A qualitative analysis of the experiences of practices in the National Demonstration Project. Ann Fam Med 2010; 8 Suppl 1: S45-S56; S92.

45 Landon BE, Gill JM, Antonelli RC, et al. Prospects for rebuilding primary care using the patient-centered medical home. Health Aff (Millwood) 2010; 29: 827-834.

46 Leventhal T, Taliaferro JP, Wong K, et al. The patient-centered medical home and health information technology. Telemed J E Health 2012; 18: 145-149.

47 Fisher E. Building a medical neighborhood for the medical home. N Engl J Med 2008; 359: 1202-1205.

48 Nutting PA, Crabtree BF, Stewart EE, et al. Effect of facilitation on practice outcomes in the National Demonstration Project model of the patientcentered medical home. Ann Fam Med 2010; 8 Suppl 1: S33-S44; S92.

49 Arend J, Tsang-Quinn J, Levine C, et al. The patient-centered medical home. History, components, and review of the evidence. Mt Sinai J Med 2012; 79: 433-450.

50 Reid RJ, Coleman K, Johnson EA, et al. The group health medical home at year two, cost savings, higher patient satisfaction, and less burnout for providers. Health Aff (Millwood) 2010; 29: 835-843.

51 True G, Butler AE, Lamparska BG, et al. Open access in the patient-centered medical home. Lessons from the Veterans Health Administration. J Gen Intern Med 2013: 28: 539-545.
52 Wise CG, Alexander JA, Green LA, et al. Journey toward a patient-centered medical home. Readiness for change in primary care practices. Milbank $Q$ 2011; 89: 399-424.

53 Fernald DH, Deaner N, O'Neill C, et al. Overcoming early barriers to PCMH practice improvement in family medicine residencies. Fam Med 2011; 43: 503-509.

54 Bitton A, Schwartz GR, Stewart EE, et al. Off the hamster wheel? Qualitative evaluation of a payment-linked patient-centered medical home $\mathrm{PCMH}$ pilot. Milbank Q 2012; 90: 484-515.

55 Bates DW, Bitton A. The future of health information technology in the patient-centered medical home. Health Aff (Millwood) 2010; 29: 614-621.

56 Alexander JA, Cohen GR, Wise CG, et al. The policy context of patient centered medical homes. Perspectives of primary care providers. J Gen Intern Med 2012; 28: 147-153.

57 Berenson RA, Rich EC. How to buy a medical home? Policy options and practical questions. J Gen Intern Med 2010; 25: 619-624.

58 Patel UB, Rathjen C, Rubin E. Horizon's patient-centered medical home program shows practices need much more than payment changes to transform. Health Aff (Millwood) 2012; 31: 2018-2027.

59 Rittenhouse DR, Casalino LP, Shortell SM, et al. Small and medium-size physician practices use few patient-centered medical home processes. Health Aff (Millwood) 2011; 30: 1575-1584.

60 Fifield J, Forrest DD, Martin-Peele M, et al. A randomized, controlled trial of implementing the patient-centered medical home model in solo and small practices. J Gen Intern Med 2013; 28: 770-777.

61 Friedberg MW, Safran DG, Coltin KL, et al. Readiness for the patientcentered medical home. Structural capabilities of Massachusetts primary care practices. J Gen Intern Med 2009; 24: 162-169.

62 Bryan A. Plotting a path to the PCEHR. MJA Careers 2012; C8-C9. https:// www.mja.com.au/careers/196/11/plotting-path-pcehr?0=ip_login_no_cach e\%3D67b9660005814c57e9bd031305d0578 (accessed Jan 2014).

63 Smith P. After-hours contracts alarm GPs. Australian Doctor 2013; 28 May. http://www.australiandoctor.com.au/news/latest-news/after-hourscontracts-alarm-gps (accessed Jan 2014).

64 Australian Commission on Safety and Quality in Health Care, Royal Australian College of General Practitioners. General practice accreditation to benefit from collaborative approach [media release]. 11 April 2014. http://www.safetyandquality.gov.au/media_releases/general-practiceaccreditation-to-benefit-from-collaborative-approach (accessed Jun 2014).

65 Sandelowski M, Barroso J. Finding the findings in qualitative studies. J Nurs Scholarsh 2002; 34: 213-219.

66 Sandelowski M, Barroso J. Handbook for synthesising qualitative research. New York: Springer; 2007.

67 Dixon-Woods M, Agarwal S, Jones D, et al. Synthesising qualitative and quantitative evidence: a review of possible methods. $J$ Health Serv Res Policy 2005; 10: 45-53. 